\title{
Immunotherapy with myeloid cells for tolerance induction
}

\author{
Mercedes Rodriguez-García ${ }^{a}$, Peter Boros ${ }^{b}$, Jonathan S. Bromberg ${ }^{c}$, and Jordi C. \\ Ochando ${ }^{\mathrm{a}, \mathrm{c}}$ \\ almmunología de Trasplantes, Centro Nacional de Microbiología, Instituto de Salud Carlos III, \\ Madrid, Spain \\ bDepartment of Surgery, Mount Sinai School of Medicine, New York, USA \\ 'Department of Gene and Cell Medicine, Mount Sinai School of Medicine, New York, USA
}

\begin{abstract}
Purpose of review-Understanding the interplay between myeloid dendritic cells and T cells under tolerogenic conditions, and whether their interactions induce the development of antigenspecific regulatory $\mathrm{T}$ cells (Tregs) is critical to uncover the mechanisms involved in the induction of indefinite allograft survival.
\end{abstract}

Recent findings-Myeloid dendritic cell-T-cell interactions are seminal events that determine the outcome of the immune response, and multiple in-vitro protocols suggest the generation of tolerogenic myeloid dendritic cells that modulate $\mathrm{T}$-cell responses, and determine the outcome of the immune response to an allograft following adoptive transfer. We believe that identifying specific conditions that lead to the generation of tolerogenic myeloid dendritic cells and Tregs are critical for the manipulation the immune response towards the development of transplantation tolerance.

Summary-We summarize recent findings regarding specific culture conditions that generate tolerogenic myeloid dendritic cells that induce T-cell hyporesponsiveness and Treg development, and represents a novel immunotherapeutic approach to promote the induction of indefinite graft survival prolongation. The interpretations presented here illustrate that different mechanisms govern the generation tolerogenic myeloid dendritic cells, and we discuss the concomitant therapeutic implications.

\section{Keywords}

immunotherapy; myeloid dendritic cells; regulatory $\mathrm{T}$ cells

\section{Introduction}

A major challenge in transplantation is to control the strong immune responses to foreign antigens that are responsible for graft rejection. Although immunosuppressive drugs efficiently inhibit acute graft rejection, a substantial proportion of patients suffer chronic rejection leading to functional loss of the graft. Induction of immunological tolerance constitutes more than just a laboratory solution for the need of lifelong treatment with immunosuppressive drugs for transplant recipients [1], and immunotherapy with myeloid dendritic cells and their precursors represent a promising tool for the establishment of

(C) 2010 Wolters Kluwer Health | Lippincott Williams \& Wilkins

Correspondence to Jordi C. Ochando, Inmunología de Trasplantes, Instituto de Salud Carlos III, 28220 Madrid, Spain Tel: +34 918223274; fax: +34 918223269; jochando@ isciii.es.

The authors declare no conflict of interest. 
indefinite allograft survival [2] Over the last years there have been an increasing number of articles that manipulated myeloid dendritic cell precursors to influence the immune response towards tolerance. Some of these articles also investigated the induction of antigen-specific tolerance using particular in-vitro culture conditions that cause T-cell hyporesponsiveness and promote regulatory T-cell (Treg) development. We have reviewed numerous strategies that are available to generate stable myeloid dendritic cells with tolerogenic properties, which include their modification with chemicals [3], cytokines [4], peptides [5]; via gene modification [6], small interfering RNA [7], and immunosuppressive drugs [8], some of which have already given promising results in macaques [9].

\section{Generation of tolerogenic myeloid cells in vitro}

\section{Immunosuppressants}

Rapamycin-Most of the experimental research with rapamycin conditioned dendritic cells for the induction of transplantation tolerance comes from Angus Thomson laboratory, which initially reported that rapamycin-treated alloantigen-pulsed dendritic cells infused 1 week before transplantation inhibits antigen-specific T-cell responsiveness and prolongs skin graft survival [10]. Similar studies reported indefinite vascularized skin allograft survival in recipient rats treated with antilymphocyte serum and cyclosporine, together with rapamycin-conditioned dendritic cells cultured with donor-derived peptide [11]. Interestingly, $\mathrm{T}$ cells from long-surviving grafts in these mice exhibit donor-specific hyporesponsiveness and expression of Foxp3 [11], which is consistent with a recent study which suggests that inhibition of mammalian target of rapamycin (mTOR) signaling during T-cell activation by rapamycin induces foxp3 in synergy with TGF- $\beta$ [12].

Mycophenolic acid-Human dendritic cells cultured with granulocyte-macrophage colony-stimulating factor (GM-CSF), IL-4, TNF-a, and mycophenolic acid (MPA) results in the generation of alloantigen-specific and contact-dependent suppressive Foxp3-expressing Tregs that secreted large amounts of IL-10 and TGF- $\beta$, and have high expression of CD 25 , glucocorticoid-induced tumor necrosis factor receptor (TNFR) [GITR], CTLA-4, and CD95 [13].

Cyclosporine A-It has been recently proposed that cyclosporine A increases the production of IL-10 in dendritic cells, and inhibits dendritic cell allostimulatory capacity by up-regulating B7 expression [14].

Dexamethasone-Human myeloid dendritic cells cultured with GM-CSF, dexamethasone, and lipopolysaccharide (LPS) produce high levels of IL-10 and reduces Th1 cytokine production [15]. Likewise, dexamethasone-stimulated human monocytes become tolerogenic dendritic cells that stimulate $\mathrm{CD}^{+} \mathrm{T}$ lymphocytes to become Treg, which inhibit antigen-specific immune responses by secreting IL-10 [16]. In rats, in-vitro generated dendritic cells cultured with GM-CSF, IL-4, and dexamethasone bone marrow cells expand Treg, whereas human blood monocytes cultured with GM-CSF, IL-4, dexamethasone, and LPS induce T-cell anergy [17]. With regards to transplantation, donor hyporesponsive dendritic cells can be generated from rat bone marrow cells with GM-CSF, IL-4, and Flt3L in the presence of dexamethasone and LPS, although they do not prolong fully allogeneic allograft survival [18].

Prostaglandin-Dendritic cells generated in the presence of GM-CSF, IL-2, and prostaglandin are more efficient than anti-CD3/CD28 mAbs in expanding Treg and prevent unwanted immune reactions to allografts, since only infusion of dendritic cell-expanded Treg suppresses recipient response to donor alloantigens [19]. 


\section{Chemicals}

Vitamin D3-Vitamin D3 (VD3)-matured dendritic cells are able to convert CD4 ${ }^{+} \mathrm{T}$ cells into IL-10-secreting antigen-specific Tregs that suppress proliferation of effector T cells [20]. When combined with LPS, human monocyte cultured in the presence of GM-CSF, IL-4, VD3, and dexamethasone generates tolerogenic dendritic cells that retain a semimature phenotype with an anti-inflammatory cytokine profile, which is important for optimizing their therapeutic potential [21]. This is of special interest, since some of the critical aspects for immunotherapy with myeloid cells suggest that tolerogenic dendritic cell maturation must be impaired, specially during potential infections or inflammatory episodes following their adoptive transfer [22,23]. With regards to the effects of VD3 on T cells, it has been recently suggested that VD3 induces a transient expression of CTLA-4 and FoxP3 in cultured human $\mathrm{CD} 4{ }^{+} \mathrm{CD} 25^{-} \mathrm{T}$ cells, which may be used to modulate the immune response [24].

Aspirin-Aspirin-treated human dendritic cells are resistant to maturation and exhibit a reduced expression of co-stimulatory molecules, such as CD40, CD80, and CD86, and increased expression of immunoglobulin-like transcript-3 (ILT3), which induces de-novo generation of Treg and promotes transplantation tolerance [3]. This is consistent with previous data, which suggest that tolerogenic myeloid cells must express low levels of cellsurface coestimulatory molecules to regulate the immune response [25].

Aryl hydrocarbon receptor-Recipient-derived mouse bone marrow cells cultured in the presence of GM-CSF, LPS, and an activator of the aryl hydrocarbon receptor, prevents islet allograft rejection by reducing antigen specific T-cell responses in the draining lymph node [26].

\section{Interleukins/cytokines}

Pioneer studies from Austin and colleagues suggested that low doses of GM-CSF in the absence of IL-4 generates allogeneic immature dendritic cells in vitro that are resistant to different maturation stimuli, induce T-cell unresponsiveness in vitro, and promote alloantigen-specific graft acceptance [27]. Similarly, human monocytes cultured with GMCSF in the absence of IL-4 generate semimature myeloid cells with low stimulatory activity [28]. Similarly, Torres-Aguilar and colleagues [4] have recently reported different ways of generating tolerogenic dendritic cells from culturing human monocytes with GM-CSF and IL-4 simultaneously with IL-10 \pm IL- $6 \pm$ TGF- $\beta 1$, which enhanced the expression of the regulatory molecules, and induced strong antigen-specific anergy in memory $\mathrm{T}$ cells. Others have suggested that GM-CSF, IL-4, and IFN- $\gamma$ human monocytes develop into maturationresistant dendritic cells that express DC-SIGN, Langerin, and CD123, and promote nonspecific Treg development [29]. With regards to transplantation, alloantigen-activated $\mathrm{CD} 4^{+} \mathrm{T}$ cells cultured in the presence of IFN $-\gamma$ promotes the generation of $\mathrm{CD} 25^{+} \mathrm{CD} 62 \mathrm{~L}^{+} \mathrm{Foxp}^{+} \mathrm{T}$ cells capable of preventing allograft rejection following adoptive transfer [30,31]. Semimature dendritic cells generated from murine bone marrow progenitors cultured with GM-CSF, IL-4, TNF- $\gamma$, and LPS, secrete low levels of IL-6 and IL-12p70, induce effector T-cell hyporesponsiveness in vitro, expand Foxp $3^{+}$Treg in vivo, prolonging skin allograft survival [32]. Murine bone marrow cells cultured with GM-CSF, IL-10, and LPS generates alternatively activated donor dendritic cells that express high levels of PD-L1, display a reduced alloreactive T-cell-stimulating capacity, and expand Foxp $3^{+}$Treg in vitro, prolonging skin allograft survival [33"]. More recently, Thomson and colleagues reported that coculture of Treg with immature donor-derived dendritic cells in medium with GM-CSF and IL-4, induces potent alloantigen-specific Treg that prolong more than $80 \%$ over 150 days cardiac graft survival in mice when combined with low-dose rapamycin [34], which suggest a feedback loop between myeloid dendritic cells and Tregs 
[35]. In rats, immature dendritic cells cultured with GM-CSF and donor cell lysates are able to induce peripheral immune tolerance to hind limbs when combined with rapamycin and antilymphocyte serum [36]. Syngeneic adherent rat bone marrow cells cultured in the presence of GM-CSF express high levels of HO-1, are poor stimulators of allogeneic T cells, and prolonged cardiac allograft survival $\left[37^{\circ}\right]$.

\section{Proteins-peptides}

Vasoactive intestinal peptide-Vasoactive intestinal peptide (VIP) generates anergic $\mathrm{T}$ cells by inducing cell cycle arrest and inhibiting cytokine production in allogeneic human $\mathrm{T}$ cells. VIP also generates Foxp3-expressing Treg from $\mathrm{CD} 4{ }^{+} \mathrm{CD} 25^{-} \mathrm{T}$ cells after allogeneic stimulation, which exerts a protective role in a mouse model of acute graft-versus-host disease (GvHD) [38]. Interestingly, dendritic cell differentiated in the presence of VIP generates IL-10-secreting $\mathrm{CD} 4^{+}$and $\mathrm{CD} 8^{+} \mathrm{T}$ cells [39], and impair allogeneic antigenspecific responses of donor $\mathrm{CD} 4^{+} \mathrm{T}$ cells in mice receiving bone marrow transplants by inducing Treg in the graft [40].

Low-dose peptide-Turner and colleagues [41] recently reported that both, GM-CSF derived immature dendritic cells, and GM-CSF and IL-4-derived mature dendritic cells presenting low dose of antigen expands Foxp $3^{+}$Treg, which depends on IL- 6 production following dendritic cell-T-cell interactions.

\section{Viral induced molecules}

Pioneer studies from Cattral and colleagues demonstrated that transfection of donor-derived bone marrow derived dendritic cells with FasL-induced hyporesponsiveness to alloantigen in vivo and prolonged 15 days the graft survival of fully mismatched cardiac allografts [42]. In mice, donor-derived dendritic cells transfected with recombinant adenovirus encoding human CTLA4Ig reduces the allogeneic T-cell stimulation in vitro, and prolongs cardiac allograft survival for 40 days when injected intravenously [43]. George and colleagues demonstrated that transfecting human dendritic cells with CTLA4 fused to the endoplasmic reticulum retention signal sequence induces antigen-specific anergy in responding $\mathrm{T}$ cells by preventing dendritic cell expression of CD80 and CD86 in the cell surface [6]. One of the most promising results uses donor-derived immature dendritic cells transfected to express soluble TNF receptor are resistant to maturation, which are unable to present antigen due to their low phagocytic properties, promote the development of IL-10 regulatory T cells in vitro, and induce long-term survival of cardiac allografts of $50 \%$ of the grafts when transferred before transplantation without further treatment [44]. The same laboratory, also investigated the induction of tolerance with IL-10 dendritic cell gene transfection, although only 30-day graft survival prolongation was observed [45]. Several studies by Vassalli and colleagues reported that gene transfer of programmed death ligand-1 Ig, indoleamine 2,3dioxygenase, and soluble IL-1R Ig fusion protein, and IL-18 binding protein to donor dendritic cells attenuates cardiac allograft rejection and prolongs cardiac allograft survival by 1 week [46-48]. More recently, lentiviral vectors have been used to genetically engineer VIP-expressing bone marrow-derived dendritic cell which reduces dendritic cell expression of proinflammatory cytokines and increases their IL-10 production following local delivery [49].

\section{Immunoglobulins}

Human dendritic cells generated in vitro in presence of CTLA4-Ig suppress T-cell proliferation by up-regulating the levels of HLA-G5 in plasma of CTLA4-Ig-treated patients, with the concomitant immunosuppressive applications [50]. 


\section{Embryonic stem cells}

There is also a great interest in manipulating the immune response using myeloid cells derived from stem cell progenitors in vitro. Human embryonic stem cells (ESCs) cultured with bone morphogenetic protein-4, GM-CSF, stem cell factor and vascular endothelial growth factor (VEGF) in serum-free media generates hESC-derived monocytic cells that can be further differentiated mature dendritic cells with GM-CSF, TNF-alpha, IL-1 $\beta$, IFN- $\gamma$ and PGE2 that generates unlimited numbers of immunogenic dendritic cells [51]. Chen and colleagues have recently reported a protocol to generate myeloid-derived suppressive cells from murine embryonic stem cells in a three-step differentiation strategy which generated embryonic bodies from HoxB4-transduced ESCs cultured with c-kit ligand conditioned medium, IL-6, and WEHI-3, followed by c-kit ligand conditioned medium, thrombopoietin, VEGF, and Flt-3L. The resulting myeloid-derived suppressor cells exhibited a strong suppressive capacity in vitro, and was able to induce indefinite allograft survival of allogeneic bone marrow transplants $\left[52^{\circ}\right]$.

\section{Generation of tolerogenic myeloid cells in vivo}

One potential risk of immunotherapy with tolerogenic dendritic cells generated in vitro is that they may switch to a T-cell-activating phenotype when encountering inflammatory signals in vivo, since the local microenvironment plays an important role in the modulation of dendritic cells [53]. Complex myeloid dendritic cell-T-cell interactions occur in defined micro-anatomic domains within secondary lymphoid organs that lead either to successful Tcell priming or T-cell unresponsiveness, due to regulatory mechanisms that include anergy, deletion, or induction of Treg. Here we summarize recent data regarding the in-vivo induction of tolerogenic dendritic cells.

\section{Chemicals}

Vitamin D3-In-vivo administration of VD3 prevents dendritic cell maturation independently of Toll like receptor (TLR) stimulation [54], and topically applied VD3 increases the suppressive capacity of Foxp $3^{+}$Treg in the draining lymph nodes [55]. Vitamin $\mathrm{D}$ analogs also prevent antigen-specific priming of alloreactive $\mathrm{CD} 8^{+} \mathrm{T}$ cells and expands antigen-specific Foxp $3^{+}$Treg following immunization [56]. In transplantation, pioneer studies of Deluca and colleagues demonstrated that in-vivo administration of VD3 markedly increases allograft survival in both murine and rat vascularized and nonvascularized transplant models [57]. A possible explanation for this is that activation of VD3 receptor reprograms dendritic cell maturation to differentiate them into tolerogenic cells [58], which can be used in vivo to induce Treg-dependent antigen-specific transplantation tolerance to murine islet allografts [59].

Aryl hydrocarbon receptor-In-vivo activation of aryl hydrocarbon receptor induces antigen-specific long-term islet allograft acceptance by promoting Treg survival and function [26].

\section{Interleukins/cytokines}

GM-CSF: In-vivo administration of mouse GM-CSF promoted the development of $\mathrm{CD} 11 \mathrm{~b}^{+} \mathrm{Gr}-1^{+}$myeloid-derived suppressor cells that prevent $\mathrm{CD} 8^{+} \mathrm{T}$-cell-mediated immune response [60]. Interestingly, GM-CSF promotes the expansion of specific myeloid derived suppressor cell (MDSC) subsets in the spleen of tumor-bearing mice that were responsible for tolerance [61]. 


\section{Proteins-peptides}

Delivering antigens specifically to DEC205 targets MHC class I T-cell responses, whereas targeting dendritic cells via 33D1 preferentially modulates MHC class II T-cell responses [62]. Lechler and colleagues have recently conjugated the 33D1 mAb with the $\mathrm{K}^{\mathrm{d}}$, which deletes antigen-specific T cells, promotes Foxp3 Treg development, and induces indefinite skin graft survival when combined with anti-CD8 mAb [63"].

\section{Conclusion}

There is a growing interest in taking dendritic cells into medicine [2]. The international Society for Dendritic Cell and Vaccine Science has recently been created (http://www.dcvaccine.org/), and the next international symposium on dendritic cells will focus on the importance of developing dendritic cell vaccines. Dendritic cell immunotherapy in transplantation utilizes dendritic cells matured in vitro under specific culture conditions that are injected intravenously later on as tolerogenic dendritic cells. This approach may not give satisfactory results in transplantation simply because myeloid dendritic cells are poorly specialized in migrating to the lymph nodes via high endothelial venules (HEVs) (reviewed in [64]). This is of special interest, since Lakkis and colleagues [65] reported 10 years ago, that the immune response to transplant antigens leading to graft rejection can be triggered in the spleen and the lymph nodes. Therefore, we think that immunotherapy with dendritic cells to induce antigen-specific transplantation must consider that tolerogenic dendritic cells need to migrate the peripheral sites where antigen-specific $\mathrm{T}$ cells proliferate, namely the spleen and the lymph nodes [66]. For nonvascularized skin transplants, we would like to propose injections of ex vivo-matured tolerogenic dendritic cells in the skin, rather than into blood, to augment the tolerogenic responses in specific skin draining lymph nodes. For vascularized cardiac transplants, we would like to propose immunotherapy with bloodcirculating cells, such as $\mathrm{CD} 8^{+} \mathrm{DC}$, monocytes, and plasmacytoid dendritic cells (pDC), which potentially control the immune response in the recipients' lymph nodes and the spleen. This is of special interest, since CD8+DC [67], monocytes [68], and pDC [69] have been suggested to participate in Treg development, and novel approaches that target specific dendritic cell subsets in vivo to promote indefinite skin allograft survival [63"]. Additionally, it is possible that HEVs may need to be activated locally [70], or systemically [71,72] to ensure efficient migration of specific dendritic cell subsets and their precursors to the lymph nodes for successful immunotherapy, bearing in mind that these activators may affect the release of potentially nonregulatory cytokines such as IL-6.

We also believe that a combination of donor and recipient dendritic cells may be necessary to achieve indefinite allograft survival in transplantation. Acute rejection is mediated by $\mathrm{CD}^{+}$and $\mathrm{CD}^{+} \mathrm{T}$ lymphocytes that recognize transplant antigens through the direct pathway of allorecognition, whereas chronic rejection is mediated by $\mathrm{CD} 4^{+} \mathrm{T}$ cells that recognize transplant antigens through the indirect pathway of allorecognition [73,74]. In this respect, Treg stimulated though both, the direct and indirect pathways of allorecognition prevent acute and chronic rejection in recipient mice preconditioned with sublethal irradiation following adoptive transfer [75], which suggest the potential use of Treg for future cell-based immunotherapy in transplantation [76]. Therefore, it seems reasonable to think that that a combination of donor dendritic cells that induce direct T-cell hyporesponsiveness, and recipient dendritic cells that induce indirect T-cell hyporesponsiveness and Treg development are both necessary for the induction of transplantation tolerance using dendritic cell immunotherapy. 


\section{Acknowledgments}

This work was supported by the Programa Ramón y Cajal RYC-2006-1588, Ministerio de Educa-ción y Ciencia SAF2007-63579, Programa José Castillejo JC2008-00065, and Programa de Investigación de Grupos Emergentes del ISCIII (to J.C.O.), and NIH R01 AI-41428, AI-72039, and the Emerald Foundation (to J.S.B.).

\section{References and recommended reading}

Papers of particular interest, published within the annual period of review, have been highlighted as:

- of special interest

-• of outstanding interest Additional references related to this topic can also be found in the Current World Literature section in this issue (pp. 000-000).

1. Wood KJ, Bushell AR, Jones ND. The discovery of immunological tolerance: now more than just a laboratory solution. J Immunol. 2010; 184:3-4. [PubMed: 20028657]

2. Steinman RM, Banchereau J. Taking dendritic cells into medicine. Nature. 2007; 449:419-426. [PubMed: 17898760]

3. Buckland M, Lombardi G. Aspirin and the induction of tolerance by dendritic cells. Handb Exp Pharmacol. 2009:197-213. [PubMed: 19031027]

4. Torres-Aguilar H, Aguilar-Ruiz SR, Gonzalez-Perez G, et al. Tolerogenic dendritic cells generated with different immunosuppressive cytokines induce antigen-specific anergy and regulatory properties in memory CD4+ T cells. J Immunol. 2010; 184:1765-1775. [PubMed: 20083662]

5. Delgado M. Generating tolerogenic dendritic cells with neuropeptides. Hum Immunol. 2009; 70:300-307. [PubMed: 19405171]

6. Tan PH, Yates JB, Xue SA, et al. Creation of tolerogenic human dendritic cells via intracellular CTLA4: a novel strategy with potential in clinical immuno-suppression. Blood. 2005; 106:29362943. [PubMed: 15994283]

7. Xiang J, Gu X, Zhou Y, et al. Administration of dendritic cells modified by RNA interference prolongs cardiac allograft survival. Microsurgery. 2007; 27:320-323. [PubMed: 17477425]

8. Turnquist HR, Raimondi G, Zahorchak AF, et al. Rapamycin-conditioned dendritic cells are poor stimulators of allogeneic CD4+ T cells, but enrich for antigen-specific Foxp3+ T regulatory cells and promote organ transplant tolerance. J Immunol. 2007; 178:7018-7031. [PubMed: 17513751]

9. Zahorchak AF, Kean LS, Tokita D, et al. Infusion of stably immature monocyte-derived dendritic cells plus CTLA4Ig modulates alloimmune reactivity in rhesus macaques. Transplantation. 2007; 84:196-206. [PubMed: 17667811]

10. Taner T, Hackstein $\mathrm{H}$, Wang $Z$, et al. Rapamycin-treated, alloantigen-pulsed host dendritic cells induce age-specific $\mathrm{T}$ cell regulation and prolong graft survival. Am J Transplant. 2005; 5:228236. [PubMed: 15643982]

11. Horibe EK, Sacks J, Unadkat J, et al. Rapamycin-conditioned, alloantigen-pulsed dendritic cells promote indefinite survival of vascularized skin allografts in association with $\mathrm{T}$ regulatory cell expansion. Transpl Immunol. 2008; 18:307-318. [PubMed: 18158116]

12. Cobbold SP, Adams E, Farquhar CA, et al. Infectious tolerance via the consumption of essential amino acids and mTOR signaling. Proc Natl Acad Sci USA. 2009; 106:12055-12060. [PubMed: 19567830]

13. Lagaraine $\mathrm{C}$, Lemoine $\mathrm{R}$, Baron $\mathrm{C}$, et al. Induction of human $\mathrm{CD} 4+$ regulatory $\mathrm{T}$ cells by mycophenolic acid-treated dendritic cells. J Leukoc Biol. 2008; 84:1057-1064. [PubMed: 18611986]

14. Geng L, Dong S, Fang Y, et al. Cyclosporin a up-regulates B7-DC expression on dendritic cells in an IL-4-dependent manner in vitro, which is associated with decreased allostimulatory capacity of dendritic cells. Immunopharmacol Immunotoxicol. 2008; 30:399-409. [PubMed: 18569092] 
15. Bosma BM, Metselaar HJ, Nagtzaam NM, et al. Dexamethasone transforms lipopolysaccharidestimulated human blood myeloid dendritic cells into myeloid dendritic cells that prime interleukin-10 production in T cells. Immunology. 2008; 125:91-100. [PubMed: 18312359]

16. Hamdi H, Godot V, Maillot MC, et al. Induction of antigen-specific regulatory T lymphocytes by human dendritic cells expressing the glucocorticoid-induced leucine zipper. Blood. 2007; 110:211-219. [PubMed: 17356131]

17. Fazekasova H, Golshayan D, Read J, et al. Regulation of rat and human T-cell immune response by pharmacologically modified dendritic cells. Transplantation. 2009; 87:1617-1628. [PubMed: 19502952]

18. Stax AM, Gelderman KA, Schlagwein N, et al. Induction of donor-specific T-cell hyporesponsiveness using dexamethasone-treated dendritic cells in two fully mismatched rat kidney transplantation models. Transplantation. 2008; 86:1275-1282. [PubMed: 19005410]

19. Zeng M, Guinet E, Nouri-Shirazi M. Comparative analysis of dendritic cells and anti-CD3/CD28 expanded regulatory T cells for application in transplantation. Transpl Immunol. 2009; 22:82-92. [PubMed: 19635560]

20. Unger WW, Laban S, Kleijwegt FS, et al. Induction of Treg by monocyte-derived DC modulated by vitamin D3 or dexamethasone: differential role for PD-L1. Eur J Immunol. 2009; 39:31473159. [PubMed: 19688742]

21. Anderson AE, Swan DJ, Sayers BL, et al. LPS activation is required for migratory activity and antigen presentation by tolerogenic dendritic cells. J Leukoc Biol. 2009; 85:243-250. [PubMed: 18971286]

22. Jonuleit H, Schmitt E, Schuler G, et al. Induction of interleukin 10-producing, nonproliferating CD4(+) T cells with regulatory properties by repetitive stimulation with allogeneic immature human dendritic cells. J Exp Med. 2000; 192:1213-1222. [PubMed: 11067871]

23. Peche H, Trinite B, Martinet B, Cuturi MC. Prolongation of heart allograft survival by immature dendritic cells generated from recipient type bone marrow progenitors. Am J Transplant. 2005; 5:255-267. [PubMed: 15643985]

24. Jeffery LE, Burke F, Mura M, et al. 1,25-Dihydroxyvitamin D3 and IL-2 combine to inhibit T cell production of inflammatory cytokines and promote development of regulatory $\mathrm{T}$ cells expressing CTLA-4 and FoxP3. J Immunol. 2009; 183:5458-5467. [PubMed: 19843932]

25. Fu F, Li Y, Qian S, et al. Costimulatory molecule-deficient dendritic cell progenitors (MHC class II+, CD80dim, CD86-) prolong cardiac allograft survival in nonimmunosuppressed recipients. Transplantation. 1996; 62:659-665. [PubMed: 8830833]

26. Hauben E, Gregori S, Draghici E, et al. Activation of the aryl hydrocarbon receptor promotes allograft-specific tolerance through direct and dendritic cell-mediated effects on regulatory $\mathrm{T}$ cells. Blood. 2008; 112:1214-1222. [PubMed: 18550851]

27. Lutz MB, Suri RM, Niimi M, et al. Immature dendritic cells generated with low doses of GM-CSF in the absence of IL-4 are maturation resistant and prolong allograft survival in vivo. Eur $\mathrm{J}$ Immunol. 2000; 30:1813-1822. [PubMed: 10940870]

28. Chitta S, Santambrogio L, Stern LJ. GMCSF in the absence of other cytokines sustains human dendritic cell precursors with $\mathrm{T}$ cell regulatory activity and capacity to differentiate into functional dendritic cells. Immunol Lett. 2008; 116:41-54. [PubMed: 18166231]

29. Eljaafari A, Li YP, Miossec P. IFN-gamma, as secreted during an alloresponse, induces differentiation of monocytes into tolerogenic dendritic cells, resulting in FoxP3+ regulatory $\mathrm{T}$ cell promotion. J Immunol. 2009; 183:2932-2945. [PubMed: 19696431]

30. Feng G, Gao W, Strom TB, et al. Exogenous IFN-gamma ex vivo shapes the alloreactive T-cell repertoire by inhibition of Th17 responses and generation of functional Foxp3+ regulatory T cells. Eur J Immunol. 2008; 38:2512-2527. [PubMed: 18792404]

31. Feng G, Wood KJ, Bushell A. Interferon-gamma conditioning ex vivo generates CD25+CD62L +Foxp3+ regulatory $\mathrm{T}$ cells that prevent allograft rejection: potential avenues for cellular therapy. Transplantation. 2008; 86:578-589. [PubMed: 18724229]

32. Fu BM, He XS, Yu S, et al. A tolerogenic semimature dendritic cells induce effector T-cell hyporesponsiveness by activation of antigen-specific CD4+CD25+ T regulatory cells that promotes skin allograft survival in mice. Cell Immunol. 2010; 261:69-76. [PubMed: 20038461] 
33•. Dai H, Zhu H, Lei P, et al. Programmed death-1 signaling is essential for the skin allograft protection by alternatively activated dendritic cell infusion in mice. Transplantation. 2009; 88:864-873. Dai and colleagues reported that bone marrow-derived dendritic cells incubated in the presence of IL-10 and LPS up-regulate PD-L1 and prolonged skin transplants 10 days when injected intravenously. [PubMed: 19935456]

34. Raimondi G, Sumpter TL, Matta BM, et al. Mammalian target of rapamycin inhibition and alloantigen-specific regulatory $\mathrm{T}$ cells synergize to promote long-term graft survival in immunocompetent recipients. J Immunol. 2010; 184:624-636. [PubMed: 20007530]

35. Darrasse-Jeze G, Deroubaix S, Mouquet H, et al. Feedback control of regulatory T cell homeostasis by dendritic cells in vivo. J Exp Med. 2009; 206:1853-1862. [PubMed: 19667061]

36. Sacks JM, Kuo YR, Taieb A, et al. Prolongation of composite tissue allograft survival by immature recipient dendritic cells pulsed with donor antigen and transient low-dose immunosuppression. Plast Reconstr Surg. 2008; 121:37-49. [PubMed: 18176204]

37•. Moreau A, Hill M, Thebault P, et al. Tolerogenic dendritic cells actively inhibit $\mathrm{T}$ cells through heme oxygenase-1 in rodents and in nonhuman primates. FASEB J. 2009; 23:3070-3077. Moreau and colleagues reported that rat-adherent dendritic cells generated from bone marrow precursors in the presence of GM-CSF express high levels of HO-1 and promote indefinite cardiac allograft survival in 25\% of the transplanted grafts. [PubMed: 19420134]

38. Pozo D, Anderson P, Gonzalez-Rey E. Induction of alloantigen-specific human T regulatory cells by vasoactive intestinal peptide. J Immunol. 2009; 183:4346-4359. [PubMed: 19734220]

39. Gonzalez-Rey E, Chorny A, Fernandez-Martin A, et al. Vasoactive intestinal peptide generates human tolerogenic dendritic cells that induce CD4 and CD8 regulatory T cells. Blood. 2006; 107:3632-3638. [PubMed: 16397128]

40. Chorny A, Gonzalez-Rey E, Fernandez-Martin A, et al. Vasoactive intestinal peptide induces regulatory dendritic cells that prevent acute graft-versus-host disease while maintaining the graftversus-tumor response. Blood. 2006; 107:3787-3794. [PubMed: 16418327]

41. Turner MS, Kane LP, Morel PA. Dominant role of antigen dose in CD4+Foxp3+ regulatory T cell induction and expansion. J Immunol. 2009; 183:4895-4903. [PubMed: 19801514]

42. Min WP, Gorczynski R, Huang XY, et al. Dendritic cells genetically engineered to express Fas ligand induce donor-specific hyporesponsiveness and prolong allograft survival. J Immunol. 2000; 164:161-167. [PubMed: 10605007]

43. Sun W, Wang Q, Zhang L, et al. Blockade of CD40 pathway enhances the induction of immune tolerance by immature dendritic cells genetically modified to express cytotoxic T lymphocyte antigen 4 immunoglobulin. Transplantation. 2003; 76:1351-1359. [PubMed: 14627915]

44. Wang Q, Liu Y, Wang J, et al. Induction of allospecific tolerance by immature dendritic cells genetically modified to express soluble TNF receptor. J Immunol. 2006; 177:2175-2185. [PubMed: 16887977]

45. Zhang M, Wang Q, Liu Y, et al. Effective induction of immune tolerance by portal venous infusion with IL-10 gene-modified immature dendritic cells leading to prolongation of allograft survival. J Mol Med. 2004; 82:240-249. [PubMed: 15168681]

46. Dudler J, Li J, Pagnotta M, et al. Gene transfer of programmed death ligand-1. Ig prolongs cardiac allograft survival. Transplantation. 2006; 82:1733-1737. [PubMed: 17198268]

47. Li J, Meinhardt A, Roehrich ME, et al. Indoleamine 2,3-dioxygenase gene transfer prolongs cardiac allograft survival. Am J Physiol Heart Circ Physiol. 2007; 293:H3415-3423. [PubMed: 17933973]

48. Simeoni E, Dudler J, Fleury S, et al. Gene transfer of a soluble IL-1 type 2 receptor-Ig fusion protein improves cardiac allograft survival in rats. Eur J Cardiothorac Surg. 2007; 31:222-228. [PubMed: 17182252]

49. Toscano MG, Delgado M, Kong W, et al. Dendritic cells transduced with lentiviral vectors expressing VIP differentiate into VIP-secreting tolerogenic-like DCs. Mol Ther. 2010; 18:10351045. [PubMed: 20068554]

50. Bahri R, Naji A, Menier C, et al. Dendritic cells secrete the immunosuppressive HLA-G molecule upon CTLA4-Ig treatment: implication in human renal transplant acceptance. J Immunol. 2009; 183:7054-7062. [PubMed: 19915057] 
51. Tseng SY, Nishimoto KP, Silk KM, et al. Generation of immunogenic dendritic cells from human embryonic stem cells without serum and feeder cells. Regen Med. 2009; 4:513-526. [PubMed: 19580370]

52. Zhou Z, French DL, Ma G, et al. Development and function of myeloid-derived suppressor cells generated from mouse embryonic and hematopoietic stem cells. Stem Cells. 2010; 28:620-632. Zhou et al. reported that myeloid derived suppressor cells generated from embryonic stem cells prevent graft-versus-host disease and induce long-term survival in $80 \%$ of recipient mice. [PubMed: 20073041]

53. Belkaid Y, Oldenhove G. Tuning microenvironments: induction of regulatory T cells by dendritic cells. Immunity. 2008; 29:362-371. [PubMed: 18799144]

54. Yates SF, Paterson AM, Nolan KF, et al. Induction of regulatory T cells and dominant tolerance by dendritic cells incapable of full activation. J Immunol. 2007; 179:967-976. [PubMed: 17617588]

55. Gorman S, Kuritzky LA, Judge MA, et al. Topically applied 1,25-dihydroxyvitamin D3 enhances the suppressive activity of CD4+CD25+ cells in the draining lymph nodes. J Immunol. 2007; 179:6273-6283. [PubMed: 17947703]

56. Ghoreishi M, Bach P, Obst J, et al. Expansion of antigen-specific regulatory T cells with the topical vitamin d analog calcipotriol. J Immunol. 2009; 182:6071-6078. [PubMed: 19414758]

57. Hullett DA, Cantorna MT, Redaelli C, et al. Prolongation of allograft survival by 1,25dihydroxyvitamin D3. Transplantation. 1998; 66:824-828. [PubMed: 9798688]

58. Szeles L, Keresztes G, Torocsik D, et al. 1,25-dihydroxyvitamin D3 is an autonomous regulator of the transcriptional changes leading to a tolerogenic dendritic cell phenotype. J Immunol. 2009; 182:2074-2083. [PubMed: 19201860]

59. Gregori S, Casorati M, Amuchastegui S, et al. Regulatory T cells induced by 1 alpha,25dihydroxyvitamin D3 and mycophenolate mofetil treatment mediate transplantation tolerance. $\mathrm{J}$ Immunol. 2001; 167:1945-1953. [PubMed: 11489974]

60. Bronte V, Chappell DB, Apolloni E, et al. Unopposed production of granulocyte-macrophage colony-stimulating factor by tumors inhibits CD8+ T cell responses by dysregulating antigenpresenting cell maturation. J Immunol. 1999; 162:5728-5737. [PubMed: 10229805]

61. Dolcetti L, Peranzoni E, Ugel S, et al. Hierarchy of immunosuppressive strength among myeloidderived suppressor cell subsets is determined by GM-CSF. Eur J Immunol. 2010; 40:22-35. [PubMed: 19941314]

62. Dudziak D, Kamphorst AO, Heidkamp GF, et al. Differential antigen processing by dendritic cell subsets in vivo. Science. 2007; 315:107-111. [PubMed: 17204652]

63•. Tanriver Y, Ratnasothy K, Bucy RP, et al. Targeting MHC class I monomers to dendritic cells inhibits the indirect pathway of allorecognition and the production of IgG alloantibodies leading to long-term allograft survival. J Immunol. 2010; 184:1757-1764. Tanriver and colleagues reported that targeting dendritic cells with an MHC class I-derived allopeptide induces indefinite skin graft survival of $60 \%$ of recipients following anti-CD8 mAb treatment. [PubMed: 20083658]

64. Randolph GJ, Ochando J, Partida-Sanchez S. Migration of dendritic cell subsets and their precursors. Annu Rev Immunol. 2008; 26:293-316. [PubMed: 18045026]

65. Lakkis FG, Arakelov A, Konieczny BT, Inoue Y. Immunologic 'ignorance' of vascularized organ transplants in the absence of secondary lymphoid tissue. Nat Med. 2000; 6:686-688. [PubMed: 10835686]

66. Reed AJ, Noorchashm H, Rostami SY, et al. Alloreactive CD4 T cell activation in vivo: an autonomous function of the indirect pathway of alloantigen presentation. J Immunol. 2003; 171:6502-6509. [PubMed: 14662850]

67. Yamazaki S, Dudziak D, Heidkamp GF, et al. CD8+CD205+ splenic dendritic cells are specialized to induce Foxp3+ regulatory T cells. J Immunol. 2008; 181:6923-6933. [PubMed: 18981112]

68. Garcia MR, Ledgerwood L, Yang Y, et al. Monocytic suppressive cells mediate transplantation tolerance in mice. J Clin Invest. 2010

69. Ochando JC, Homma C, Yang Y, et al. Alloantigen-presenting plasmacytoid dendritic cells mediate tolerance to vascularized grafts. Nat Immunol. 2006; 7:652-662. [PubMed: 16633346] 
70. Dawicki W, Jawdat DW, Xu N, Marshall JS. Mast cells, histamine, and IL-6 regulate the selective influx of dendritic cell subsets into an inflamed lymph node. J Immunol. 2010; 184:2116-2123. [PubMed: 20083654]

71. Janatpour MJ, Hudak S, Sathe M, et al. Tumor necrosis factor-dependent segmental control of MIG expression by high endothelial venules in inflamed lymph nodes regulates monocyte recruitment. J Exp Med. 2001; 194:1375-1384. [PubMed: 11696601]

72. Yoneyama H, Matsuno K, Zhang Y, et al. Evidence for recruitment of plasmacytoid dendritic cell precursors to inflamed lymph nodes through high endothelial venules. Int Immunol. 2004; 16:915928. [PubMed: 15159375]

73. Boisgerault F, Liu Y, Anosova N, et al. Differential roles of direct and indirect allorecognition pathways in the rejection of skin and corneal transplants. Transplantation. 2009; 87:16-23. [PubMed: 19136886]

74. Illigens BM, Yamada A, Anosova N, et al. Dual effects of the alloresponse by Th1 and Th2 cells on acute and chronic rejection of allotransplants. Eur J Immunol. 2009; 39:3000-3009. [PubMed: 19658090]

75. Joffre O, Santolaria T, Calise D, et al. Prevention of acute and chronic allograft rejection with CD4+CD25+Foxp3+ regulatory T lymphocytes. Nat Med. 2008; 14:88-92. [PubMed: 18066074]

76. Sayegh MH, Weiner HL. Regulating rejection with cell therapy. Nat Biotechnol. 2008; 26:191192. [PubMed: 18259174] 